\title{
Corporal Punishment in Children and its Implications on Mental Health
}

\author{
Kushagra Nijhara $^{1,2}$ (D) $\cdot{\text { Snigdha } \text { Bhatia }^{3} \cdot \text { B. Unnikrishnan }}^{4}$
}

Received: 14 September 2017 / Accepted: 4 October 2017 /Published online: 10 November 2017

(C) Dr. K C Chaudhuri Foundation 2017

To the Editor: In spite of a high index of suspicion, corporal punishment of children continues to exist in homes and schools worldwide. Many studies over the past have established the crippling effect of physical force to discipline children but it is still considered normal to slap, spank, hit, push and grab children to instill fear and curb behavior.

Witnessing and experiencing violence during formative years is seen to have a permanent impact on a child's mindset. Studies have shown that adults with chronic physical and mental health disorders as well as delinquency and emotional instability have had exposure to abusive stressors in their childhood [1]. The knowledge and extensive study of this in developed countries has resulted in a strong child and protective services division in their healthcare system and is not taken lightly. This is a wake-up call for parenting and schooling in developing countries like India, where such corporal punishment is not considered a form of abuse but rather an age-old norm of discipline and training children. Studies have shown that contrary to societal beliefs, mild corporal punishment too has an impact on a child's well being [2]. It is possible that children intuitively suppress their emotional and mental needs in fear of being reprimanded and this may be a

Kushagra Nijhara

knijhara@gmail.com

1 Jawaharlal Nehru Medical College (KLE University), Belgaum, India

2 43, NRI Complex, Alaknanda, New Delhi 110019, India

3 Kasturba Medical College (Manipal University), Mangalore, India

4 Department of Community Medicine, Kasturba Medical College (Manipal University), Mangalore, India cause of under-diagnosis of childhood mental disorders [3]. This also results in anxiety and malingering to avoid school, lack of help-seeking behavior and more importantly, an attitude of complacency towards violence in the adult years [4].

The implications of these facts are far-reaching. Awareness among the masses that such practices do amount to abuse, is necessary. A higher index of suspicion among pediatricians in India regarding such domestic and school-related issues is imperative and detailed counseling of the parents should be done. Pediatricians should be mindful that this may be the cause of several health issues a child is brought to the doctor with. Creative alternative forms of discipline might go a long way in eliminating this practice. It is only when the social norms and perception towards such methods will change, that such practices can finally be eradicated.

\section{Compliance with Ethical Standards}

Conflict of Interest None.

Source of Funding None.

\section{References}

1. Afifi TO, Mota N, MacMillan HL, Sareen J. Harsh physical punishment in childhood and adult physical health. Pediatrics. 2013;132: e333-40.

2. Font SA, Cage J. Dimensions of physical punishment and its associations with children's cognitive performance and school adjustment. Child Abuse Negl. 2017; https://doi.org/10.1016/j.chiabu.2017.06.008.

3. Singhi P, Saini AG, Malhi P. Child maltreatment in India. Paediatr Int Child Health. 2013;33:292-300.

4. Noll JG, Shenk CE. Introduction to the special issue: the physical health consequences of childhood maltreatment- implications for public health. J Pediatr Psychol. 2010;35:447-9. 